\title{
The meaning of modern audiological tests in relation to noise-induced deafness: a review
}

\author{
T. J. WILMOT \\ Consultant Otologist West Tyrone and Fermanagh; Neuro-otologist to Claremont \\ Street Hospital, Belfast
}

Wilmot, T. J. (1972). Brit. J. industr. Med., 29, 125-133. The meaning of modern audiological tests in relation to noise-induced deafness: a review. If noise-induced deafness becomes a prescribed disease, it is inevitable that a very large number of workers with hearing difficulties will be discovered and will pose serious problems for both industrial medical officers and otologists working in the National Health Service.

The two main problems are detection of deafness and a decision whether the hearing loss is attributable to noise damage. This paper is concerned largely with the second problem, and outlines in general terms the procedures likely to be required.

After a short discussion of the initial screening procedure the paper concentrates upon those who fail to pass the requisite standard, and describes how modern hearing tests help to differentiate between various types of hearing loss. The traditional belief that conductive deafness and sensorineural deafness are easily differentiated holds true only in classical examples. In practice, in many cases, there are often mixed elements of both. In these individuals the acoustic impedance meter may give important objective evidence on the functions of the Eustachian tube, the tympanic membrane and ossicular chain, and the small but important intratympanic muscles.

Even a pure sensorineural deafness may be present without being caused by noise, and the uses of speech tests and tests for 'recruitment' are invaluable in the differential diagnosis of this type of hearing loss.

Whereas noise-induced deafness is usually bilateral, unilateral deafness can be caused or aggravated by noise, and our problems are increased in these cases as efficient 'masking' of the good ear is essential before we can obtain any true information about the impaired hearing ear.

One of the other problems is malingering. This may be deliberate, or a person with good hearing may believe it to be impaired; both varieties are now usually known as non-organic hearing loss. Usually the simplest differentiating factor is the ability of someone with nonorganic hearing loss to hear the spoken word much more easily than pure tones, and this sign should always make one suspicious of this type of disorder.

Modern auditory analysis should enable the otologist who is equipped with suitable apparatus to diagnose with some precision the site and extent of most auditory disorders and to evaluate the proportion of noise-induced hearing loss in each individual affected.

The whole question of environmental pollution is of topical interest, and one of the agents responsible is noise (Bell, 1966; Burns, 1968). Noise both disturbs the environment and, when excessive, damages the hearing mechanism.

Its harmful effects on human hearing have been 
known for many years (Barr, 1886; Glorig, 1958), and permanent noise-induced deafness as the result of various occupations, both civilian and military, ancient and modern, has increasingly been recognized (Burns and Robinson, 1970; Coles and Knight, 1965; Taylor, Pearson, Kell, and Mair, 1967; Kerr, 1967). Such occupational noise trauma results in a sensorineural loss of hearing of varying degree, depending upon the noise level and the duration of exposure to the noise. Minor exposures cause temporary loss of hearing (temporary hearing threshold shift) with recovery, some individuals proving more susceptible than others to this type of hearing loss. Excessive noise, continued for long periods, will reduce permanently (permanent hearing threshold shift) the hearing of even the most resistant individual unless the ears are adequately protected. This is to say, a combination of noise intensity and duration, i.e., the noise immission, will at a certain level permanently damage human hearing.

Although some other countries now offer compensation for noise-induced deafness acquired in the course of an individual's occupation (Bell, 1966), sometimes on the basis of loss of earning power, this is still not the case in the United Kingdom where the Industrial Injuries Act works on a different principle. Only under common law, if negligence by an employer has been proved in the courts, can compensation at present be obtained.

The practical difficulties involved in including industrial deafness among the prescribed diseases are immense (Symons, 1958; Hayes, 1958; White Paper, 1969). First, to establish that a particular noise immission has caused hearing loss, it is necessary to obtain an accurate assessment of the noise level to which a claimant has been exposed and a reliable history of the duration of exposure. Both these factors may be difficult to confirm. Secondly, the complex problem of other pathological conditions arises.

There are over 19 million persons employed in factories in the UK alone with perhaps up to half of them in industries where there is a noise hazard so that the physical task involved in effective widespread screening of hearing in the at-risk workers is immense.

An industrial medical officer and his staff, tackling the problem of auditory screening of noise-exposed persons, will require expertise in the examination of ears and in wax removal together with guidance in the detection of hearing losses and in the significance of temporary and permanent hearing threshold shift. He may also be responsible for instructing subjects in the proper performance of the hearing tests involved and have to account to management for the installation and servicing of the necessary equipment.
If, whatever the difficulties, noise-induced deafness is made a prescribed disease, it seems certain that a very large number of individuals with hearing loss will be detected, whether or not this is due to an occupational hazard. At this stage, the problem moves from the industrial medical officer to the otologist. His job would be to decide whether or not an individual's hearing loss is attributable to noise damage.

If the initial screening is an industrial problemand there is as yet no legal obligation on any industry to implement this-the second or specialist screening will have repercussions upon the National Health Service. Some form of national standardization seems essential, and the setting up of regional medical boards may be required.

Even after these requirements have been met, doubtful cases will remain, and in these, further auditory and other tests will be necessary to establish more accurately the nature of the hearing loss and to exclude certain types of non-organic deafness. This, the third and final examination, will be done in specialized units practising advanced audiology.

Such a three-tier organization seems the minimum essential if this immensely complex problem is to be tackled realistically, and if justice is to be done to each individual affected.

In this context it is pertinent to point out that Noble (1970) challenges the whole concept of assessing individual hearing loss by pure-tone testing or even by traditional speech hearing tests. He believes that hearing loss is a very complicated matter which produces both a social and a working 'threshold of handicap' at the lower limits of abnormality and that these can best be found by use of a questionnaire. Such an approach with coincident emphasis upon accurate measurement of harmful noise levels may prove to be the best way of focusing attention on future prevention of hearing loss, but it does little to solve the problems of compensation for those already affected, or to assess the present overall picture.

Having briefly studied the background, we will now consider the audiological problems involved and the appropriate tests which are required.

\section{Initial screening}

Initial screening, if necessary, would be the responsibility of industrial management. An industrial medical officer, to whom this task is delegated, would have to weigh up the size of his individual problem and take appropriate administrative action to ensure that the screening of those requiring it is both physically possible and properly performed.

Self-operated pure-tone audiometers (e.g., the Rudmose) are likely to prove the equipment of choice in any large industry (Hinchcliffe, 1959; 
Fox, 1960). Audiometers manually operated by trained technicians are satisfactory where small numbers are concerned, and reduce the capital outlay involved, but they are more expensive in the long run. All audiometers must normally be used in sound-proofed rooms or booths where the ambient noise level is not more than $\mathbf{3 0}$ decibels, although modern improvement in earphone design (e.g., the Amplivox Audiocaps) to cut out excessive ambient noise has widened the conditions under which testing can take place.

There is wide choice in initial screening as to whether two or three frequencies only or the whole range of frequencies are tested. If the threshold is normal at $4000 \mathrm{~Hz}$, it is almost certain $(98 \%)$ that the rest of the hearing is normal (Glorig and House, 1958).

It is also true, however, that hearing losses confined to $4000 \mathrm{~Hz}$ or above have little effect upon the hearing of speech and that the important speech frequencies are 1000,2000 , and $3000 \mathrm{~Hz}$. An average loss of $40 \mathrm{~dB}$ in the better ear at these frequencies is probably the minimum level at which a real disability exists. The present recommendation of the British Association of Otolaryngologists ${ }^{1}$ is in favour of screening the whole range (500 to $6000 \mathrm{~Hz}$ ) with air-conducted pure tones.

If initial screening is to be done $\mathbf{4 8}$ hours or more after noise exposure (Ward, 1963), this poses further problems. Ninety per cent of the temporary threshold shift (TTS) has usually recovered in this time interval, although the remaining $10 \%$ loss may recover slowly over weeks, months or even years (Atherley and Noble, 1967).

The effects of age in producing hearing loss of a characteristic type are well known, and this must be taken into account when screening audiograms are being examined. How exactly this should be done is undecided, but reference to an agreed scale seems likely. Schneider and his colleagues (1970) point out that men with similar first-measured hearing losses, regardless of age, lose hearing in noisy surroundings at approximately the same rate; they stress that a person's pre-exposure hearing appears to be more important than his age, and that any reserve hearing should be protected.

\section{Failed screening}

We must next consider those who fail this simple type of hearing test. At this stage we do not know whether the hearing loss is conductive or sensorineural or a combination of both, or whether it is partly due to age effects or even whether it is genuine. Therefore, the subject should next be

${ }^{1}$ Report of the Occupational Deafness Committee of the British Association of Otolaryngologists, 1970. examined by an otologist who will eliminate acute or chronic ear disease and who will decide on the strength of the history, of his clinical examination, and of the screening audiogram what further tests are necessary. Simple tuning-fork tests help to differentiate conductive from sensorineural deafness, but quantitative information is also required.

The otologist starts by obtaining air and bone conduction audiograms performed by a technician using accurately calibrated equipment. Air conduction testing is straightforward, and bone conduction testing also is simple provided there is no appreciable difference in the threshold between the two ears; if such a difference is present, careful 'masking-out' of the better ear function while testing the worse ear is essential (Hood, 1962; Naunton, 1963). This calls for special skills.

Noise-induced deafness normally produces a bilaterally equal sensorineural loss, and large differences in threshold between the two ears will not be common. Unusual circumstances can, however, cause this, and other cases will arise where the noise effects have involved ears starting with different thresholds. It is also important to realize that bone-applied sounds are conducted equally to the two ears, and that a totally deaf ear will appear to hear when tested in this way unless the function of the other (good) ear is temporarily ruled out by a suitable 'masking' noise applied to this (good) ear.

The air and bone conduction tests will confirm and provide a measurement of the degree of conductive and sensorineural hearing loss present, either singly or as part of a 'mixed' deafness.

\section{Analysis of conductive deafness}

If a pure conduction loss is present with an intact tympanic membrane, this cannot be attributed to noise damage, and such cases will not be eligible for compensation or benefit. They could, therefore, be disregarded except for providing important information which is applicable to problem cases of mixed conductive and sensorineural deafness. The equipment necessary is the relatively inexpensive Acoustic Impedance Meter (Brooks, 1968 and 1969; Alberti and Kristensen, 1970; Jerger, 1970) and again a trained technician is essential.

A sound-producing probe is sealed into the external auditory meatus of the ear under test. A fixed pure tone reflected off the tympanic membrane shows the latter to have optimal compliance when pressure is equal in the middle ear and external auditory meatus. Thus positive pressure in the meatus will push the membrane inwards and reduce its compliance; similarly, negative pressure in the meatus will pull the membrane outwards with the same result. If, nowever, there is already a patho- 
logical negative pressure in the middle ear, negative pressure applied in the meatus can be adjusted until the membrane is in the optimal position where its compliance will be increased. Plotting the compliance against pressure effects will, therefore, give a clear indication of the state of the membrane and of the middle ear. This is known as tympanometry. The pressure at the point of maximum compliance represents the middle ear pressure at the time of examination.

Reduced compliance-at all pressures-will occur with tympanosclerosis, causing a rigid membrane, and with otosclerotic fixation of the ossicular chain, and with fluid in the middle ear. In the latter case there will be a shift of the curve also to the left (negative pressure) side.

Increased compliance will occur when there is a traumatic or pathological loss of continuity of the bony ossicular chain.

Typical tympanograms are illustrated diagrammatically (Figs 1 to 4 ).

The clinical uses of this equipment are well described by Alberti and Kristensen (1970) and Jerger (1970).

The impedance meter is very sensitive to pressure changes in the middle ear so that swallowing or autoinflation (Valsalva's manoeuvre), which should produce such changes, can readily be seen to do so.
Absence of needle flicker in these circumstances implies dysfunction of the Eustachian tube at the time of testing.

The tiny middle ear muscles also produce changes visible on the meter. The tensor tympani is innervated by the trigeminal nerve and can be activated by a sudden puff of air directed to the opposite eye or ear, whereas the stapedius muscle is supplied by the facial nerve and is activated by a sudden noise applied to the opposite ear. A reflex contraction of the stapedius muscle on both sides occurs in the normal individual although we are concerned only with the ear in which the acoustic measuring probe is present. A characteristic flicker of the meter needle will be seen and proves that the opposite ear has heard the sound, that the nerve pathways on both sides are intact, and that the stapes bone is not fixed on the side under test. All this information may be extremely relevant to the otologist.

The great advantage of this equipment is that the tests are completely objective. It will be appreciated that in a case of mixed deafness it is helpful to know as much as possible about the state of the middle ears, tympanic membranes, and Eustachian tubes (Wilmot, 1969; Lidén, 1969). As will be explained later, objective confirmation of sensorineural deafness characteristics can also be obtained with the impedance audiometer.
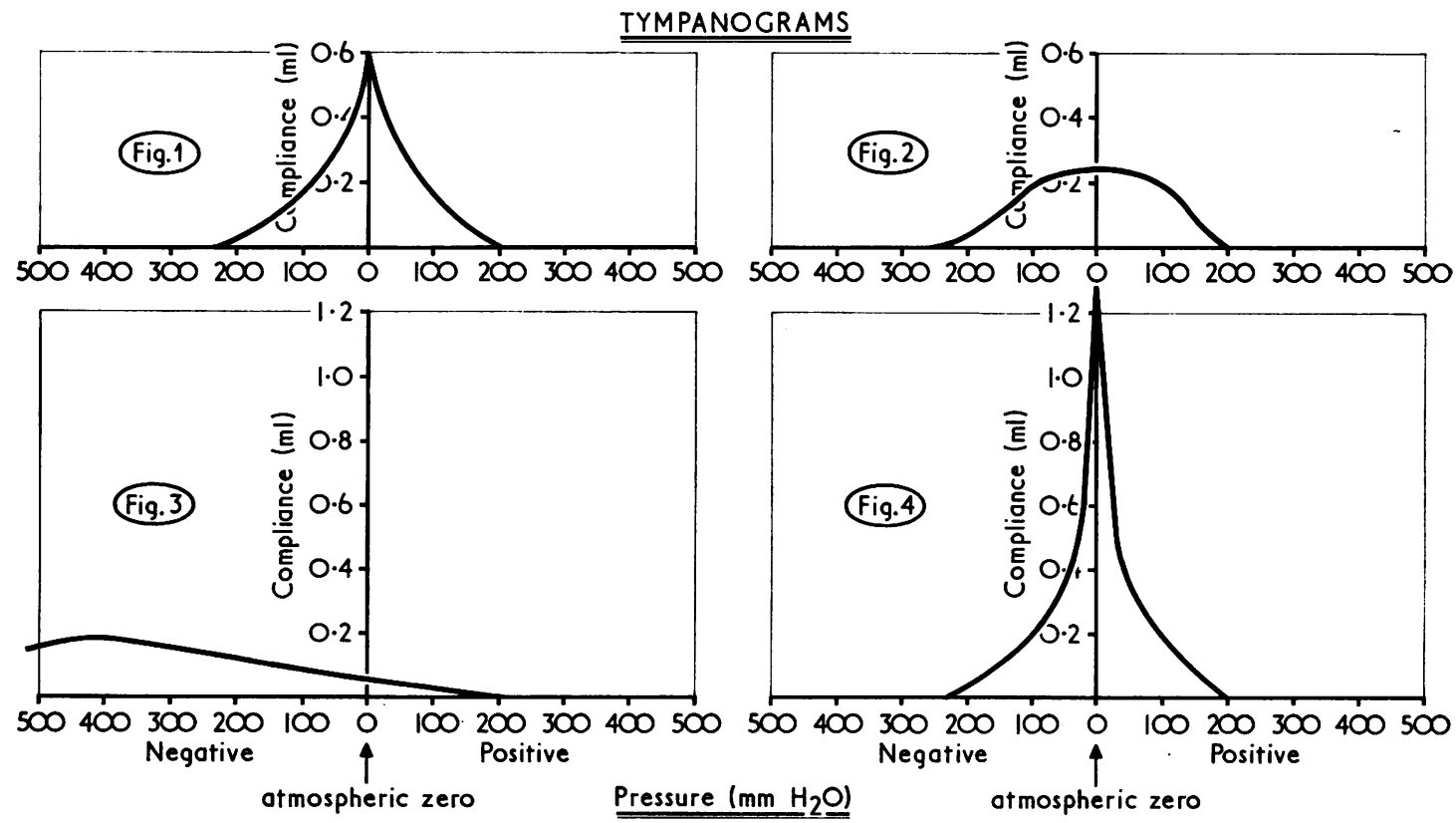

Fig. 1. Normal

FIG. 3. Fluid in middle ear cavity.

Fig. 2. Ossicular chain fixation.

Fig. 4. Ossicular chain dislocation. 


\section{Analysis of sensorineural deafness}

If a pure sensorineural deafness is present, it is important to know whether the defect is situated in the end organ (cochlea) or more centrally. Noiseinduced deafness occurs in the cochlea and shows, in its early stages, the typical characteristics of a peripheral type of deafness. When the deafness is profound, such characteristics may not be evident.

The main differentiating point between cochlear and retrocochlear deafness is the presence of 'recruitment' in the former and its absence in the latter. Loudness recruitment (Fowler, 1936) is the ability of a deaf ear to hear relatively efficiently once the (raised) threshold of sound has been reached. This happens in noise-induced deafness, but only at the frequencies damaged and only in the earlier stages of the disorder. In noise-induced deafness the higher notes are always worse affected, often showing the greatest loss around $4000 \mathrm{~Hz}$, although Schneider and his colleagues (1970) state that $6000 \mathrm{~Hz}$ is the frequency most sensitive to damage. Such a loss may occur in the presence of normal or almost normal lower and middle tone hearing, and in this case the beneficial effect of recruitment is minimal while the distortion effect produced by the grossly unequal thresholds for high and low tones may be considerable. This is, of course, why an electrical hearing aid may be of little practical assistance in this type of case.

The easiest way of testing for recruitment is to use the 'Loudness Discomfort Level' test, described by Hood and Poole (1966). This can be done with an ordinary clinical audiometer although it is helpful if the output can be boosted to $120 \mathrm{~dB}$ as the discomfort level is commonly 80 to $90 \mathrm{~dB}$ above threshold level in normal or conductively deaf subjects. The discomfort level is not synonymous with the 'pain' level which is commonly $130 \mathrm{~dB}$ or more above threshold. In the recruiting ear, as little as 30 to $\mathbf{4 0} \mathrm{dB}$ above threshold may cause discomfort.

This test also provides a simple check on threshold hearing as someone simulating deafness may appear to have a threshold of 70 or $80 \mathrm{~dB}$ at a particular frequency and show clear evidence of discomfort perhaps with an increase of stimulus of only another 10 or $20 \mathrm{~dB}$. Such extreme narrowing of the two threshold levels never occurs with organic deafness.

\section{'Fowler's binaural loudness balance' test}

This is another method of showing the presence or absence of recruitment. It has one disadvantage-it requires a definite difference in threshold between the two ears which the discomfort level test does not.

Essentially, a pure tone is provided in the good ear just above threshold and the same tone is increased to the worse ear until the sounds are of equal loudness when the decibel levels are read in the two ears. The sound is then increased $10 \mathrm{~dB}$ in the good ear, and again matched in the worse ear. The process is repeated and the results are plotted.

With a typical non-recruiting deafness, such as occurs in middle-ear disease, the difference between the thresholds of the two ears does not vary with the level of sound intensity. Thus an impaired left ear, just appreciating a tone of $1000 \mathrm{~Hz}$ at the $50 \mathrm{~dB}$ level, hears it just equal to a 0 to $5 \mathrm{~dB}$ intensity level in the normal right ear; if we put $100 \mathrm{~dB}$ of the same sound into the left ear the right ear will balance it at an intensity of $50 \mathrm{~dB}$. Intermediate levels are balanced similarly (Fig. 5).

In typical recruiting deafness, on the other hand, we may find that the impaired left ear balances the good ear at only 30 or $40 \mathrm{~dB}$ above its threshold (Fig. 6). It may even become more efficient than the good ear and may cross the median axis; this is known as over-recruitment (Fig. 7).

Certain types of sensorineural deafness show negative recruitment or a tendency for the efficiency of the impaired ear to become less with higher levels of pure tone intensity. This occurs particularly in cases of retrocochlear pathology (Fig. 8) and most typically with an VIII nerve tumour (acoustic neuroma).

The loudness balance test can, of course, be used at other frequencies and is a reliable but timeconsuming test.

Bekesy self-recording audiometry also gives reliable and valuable information in cases of sensorineural deafness (Jerger, 1960). The equipment (e.g., the Rudmose audiometer) can be used to produce 'sweep audiograms' where the pitch of the tone starts low and gradually goes up through the auditory range. The subject controls the intensity by pressure on a finger button, pressure increasing the intensity and release of pressure reducing it, so that he plots on an up and down zigzag line his own hearing threshold. This can be done for both continuous pure tones and interrupted pure tones of the same frequency. Whereas the normal individual should get the same result with both (Fig. 9), we find in cases of sensorineural deafness that the threshold may be quire different for the two types of sound. When there is recruitment present the range of excursion of the pen recorder may be much reduced with the continuous sound, although the line may be plotted below the intermittent sound line, i.e., actual threshold is increased. This reduced pen excursion means that the ear under test is appreciating very small changes in decibel intensity -often as little as one decibel, and is in fact far more sensitive than a normal ear (Fig. 10), i.e., it is 'recruiting'.

Such a sweep test for the whole range of hearing for both interrupted and continuous tones is time- 
ALTERNATE (Fowler) BINAURAL LOUDNESS BALANCE
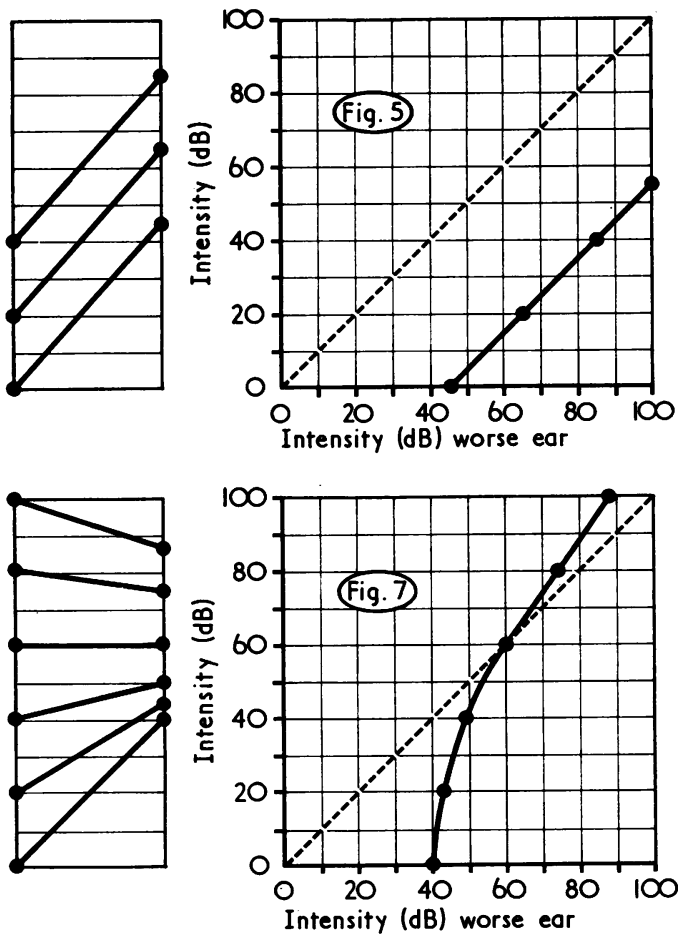

Fig. 5. Conductive (non-recruiting) deafness.

Fig. 7. Over-recruitment.

consuming and fatiguing for the subject. This type of equipment can, however, be adjusted to perform at certain fixed frequencies only. Usually 250, 1000 and $4000 \mathrm{~Hz}$ are chosen, and the test is run with both interrupted and continuous tones at these frequencies for 3 minutes each, making the total test time 18 minutes. This again is time-consuming but has, in our view, advantages over the sweep method. First, the sudden changes of frequency from 250 to $1000 \mathrm{~Hz}$ and from 1000 to $4000 \mathrm{~Hz}$ are a stimulus to patient concentration, itself all-important in this type of test. Secondly, holding each frequency 'fixed' for 3 minutes appears to assist the differentiation between the responses to continuous and intermittent signals. For instance, the reduced pen movement with the continuous signal is often more readily visible, especially at $4000 \mathrm{~Hz}$, in Ménière's disease in which recruitment is characteristic. Similarly, if marked 'tone decay' is shown the lesion is probably retrocochlear. Tone decay is made evident by a normal response to the intermittent signal accompanied by a rapid falling away of the pen with this continuous signal as more and more intensity of sound is required to register as audible to the subject (Fig. 11).

Non-organic deafness also tends to produce a
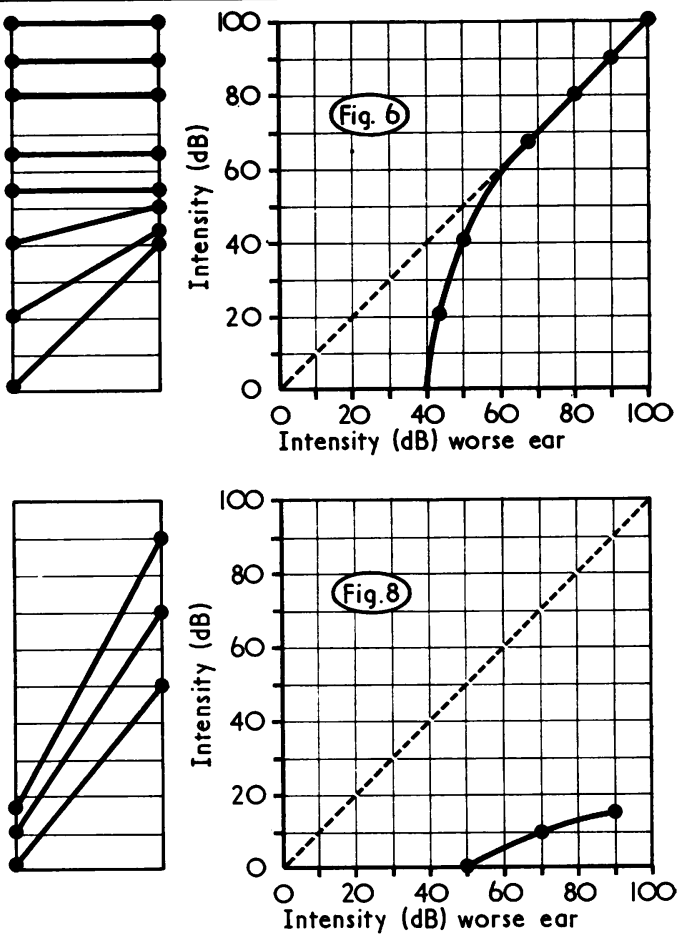

Fig. 6. Positive recruitment.

Fig. 8. Negative recruitment.

characteristic type of tracing where the continuous tones are heard better than the interrupted tones (Jerger, 1960; Hattler and Schuchman, 1970) (Fig. 12).

The phenomena of recruitment and of tone decay can also be shown very clearly (and objectively) using the acoustic impedance meter and the reactions of the stapedial muscles. If a reflex is obtained at a simulation level much less than the normal $70 \mathrm{~dB}$ above threshold required, recruitment must be present; if the reflex cannot be maintained with continued stimulus for a 20 -second period, it strongly suggests tone decay.

We have, therefore, now with advanced pure-tone audiometry distinguished a conductive from a sensorineural deafness; we have been able to localize the site of the lesion in a conductive deafness; we have seen that there are essential differences between peripheral (cochlear) sensorineural deafness and more central (retrocochlear) deafness; and we have been able to show some of these characteristics visually using self-recording (Bekesy) audiometry.

What we have not yet done is to show the significance of hearing loss in terms of social and professional adequacy. To do this we must either convert pure-tone losses into equivalent speech 


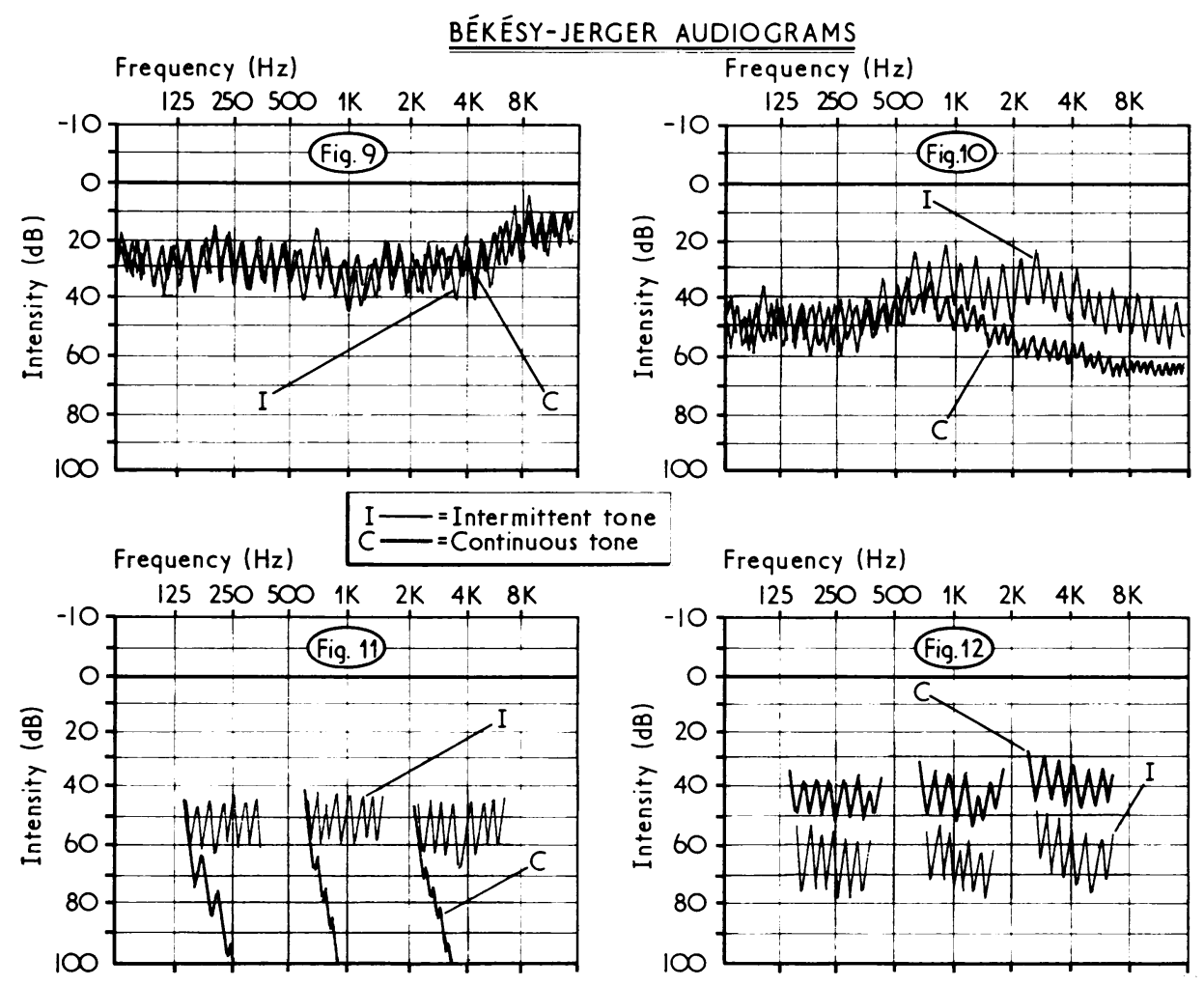

Fig. 9. Normal or conductive deafness. FIG. 11. Retrocochlear.

FIG. 10. Cochlear.

FIG. 12. Psychogenic.

hearing levels or re-assess the subject's hearing in terms of actual spoken speech. The latter is, of course, preferable and properly performed gives further information as to both the degree of loss and the character of the loss.

Speech audiometry is performed by seeing what score of correct results is obtained when a list of monosyllabic words is delivered through an audiometer. This can be done in free field conditions when both ears operate together, or through earphones when each ear can be tested individually. The speech intensity can be fixed at a single reasonable level above the pure-tone threshold (e.g., $30 \mathrm{~dB}$ ) and the result portrayed as a percentage correct score of words or phonemes, or the threshold can be varied and the result plotted in the form of a speech audiogram. Normal speech interpretation follows a characteristic curve (Fig. 13). The curve, when a conductive deafness is present, follows exactly the same pattern but is shifted to the right owing to the greater intensity of speech required for correct interpretation (Fig. 14).

With sensorineural deafness, however, the shape of the curve itself becomes altered. Generally speaking, peripheral (cochlear) losses of minor or moderate degree approximate more to the normal pattern (Fig. 15) while central (retrocochlear) losses show gross abnormalities with very little improvement in perception occurring with higher amplification (Fig. 16). Mixed lesions tend to produce intermediate type curves. Thus in Ménière's disease, where there is a cochlear lesion, the amplified speech is usually well heard, whereas in a case of acoustic neuroma, or brain stem lesion, there may be an almost total inability to repeat any word or phoneme correctly. In noise-induced deafness the picture will vary according to the extent of the damage.

With this type of test we can assess the degree of difficulty the subject has in understanding speech and also whether or not he is likely to obtain benefit from the use of an electric hearing aid, but we must also realize that there are certain technical problems involved in speech audiometry - and there is a greater tendency to subjective error than in pure-tone testing.

It is probable that the actual degree of disability, as assessed by medical boards in the future, will be based on a combination of pure-tone and speech audiometry. In relation to the latter, the beginning of handicap is around $10 \%$ of speech discrimination 

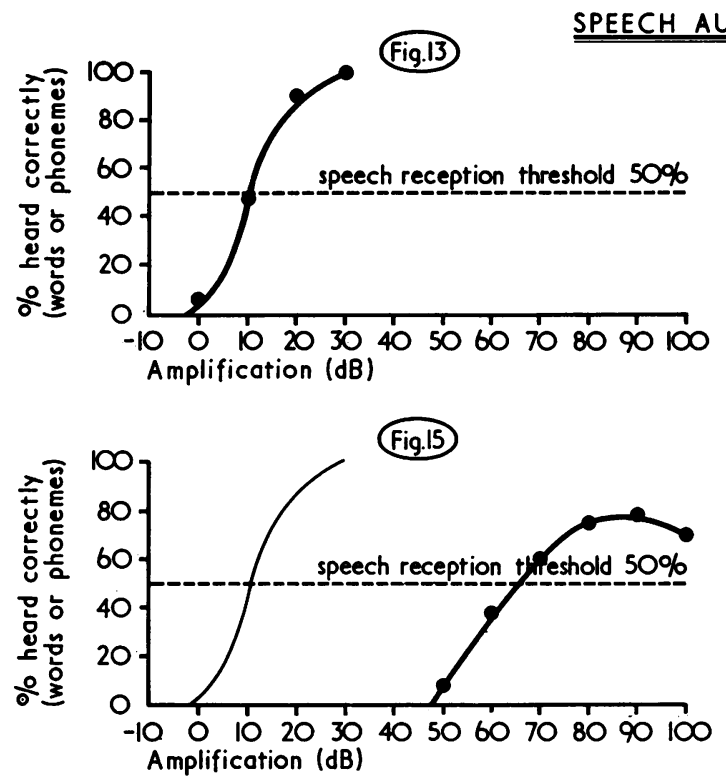

Fig. 13. Normal curve.

Fig. 15. Cochlear.

or a $30 \mathrm{~dB}$ elevation of the speech reception threshold.

\section{Discussion}

The programme of tests on each individual will, of course, depend upon the apparent loss of hearing found initially. Massive inconsistencies between pure-tone and speech-test results may suggest nonorganic deafness. In these cases the hearing usually appears to be far better to speech than to pure tones. We have already, in this connexion, mentioned the loudness discomfort level test, the Bekesy interrupted and continuous tone test, and the stapedial reflex test (with the acoustic impedance audiometer) as all helping to pick out the cases of non-organic deafness. The Stenger test describes a useful additional way of applying loudness balance to pick out such offenders (Stenger, 1956; Coles, 1971) and in extreme cases, where further objective evidence is required, evoked response audiometry (Cody, Griffing, and Taylor, 1968; Beagley and Kellogg, 1970) may be required.

It will by now be appreciated that, with the modern range of hearing tests, it is possible accurately to confirm the nature of any particular hearing loss and often indeed to localize the lesion to an individual part or parts of the hearing mechanism and nervous pathway. This is of particular importance when one realizes that many of those with noise-induced deafness may have had coincident ear disease before, during or after exposure to the damaging noise itself and that this may have affected one ear or both.

It will also be apparent that much time may be consumed during this analytical process, particularly if we accept the fact that variability of audiograms in the same individual is the rule rather than the exception and that it may be necessary to take an average reading rather than judge the issue on the result of a single audiogram. These aspects are discussed under 'Assessment of disability' by Bell (1966).

\section{Conclusion}

Audiological testing is now becoming a science, objective tests being developed to support the subjective findings.

The widespread application of these tests and their interpretation may be of considerable importance in the near future in relation to noise-induced deafness. This will especially be the case should this condition become a prescribed disease.

I wish to thank Dr. J. C. Graham of London for invaluable advice and information, and Mr. R. H. Allen, my chief technician, for the diagrams.

\section{References}

Alberti, P. W. R. M., and Kristensen, R. (1970). The clinical application of impedance audiometry. Laryngoscope, $\mathbf{8 0}$, 735-746. 
Atherley, G. R. C., and Noble, W. G. (1967). Recent developments in audiometry. Ann. occup. Hyg., 10, 389-399.

Barr, T. (1886). Enquiry into the effects of loud sounds upon the hearing of boilermakers and others who work amid noisy surroundings. Proc. phil. Soc. Glasgow, 17, 223-239.

Beagley, H. A., and Kellogg, S. E. (1970). A survey of hearing by evoked response audiometry in a group of normally hearing schoolchildren. J. Laryng., 84, 481-493.

Bell, A. (1966). Noise, an Occupational Hazard and Public Nuisance. Public Health Papers No. 30. W.H.O., Geneva.

Burns, W. (1968). Noise and Man. John Murray, London.

- and Robinson, D. W. (1970). Hearing and Noise in Industry. (Department of Health and Social Security.) H.M.S.O., London.

Brooks, D. N. (1968). An objective method of detecting fluid in the middle air. Int. Audiology, 7, 280-286.

- (1969). The use of the electro-acoustic impedance bridge in the assessment of middle ear function. Int. Audiology, 8, 563-569.

Cody, D. T. R., Griffing, T., and Taylor, W. F. (1968). Assessment of the newer tests of auditory function. Ann. Otol. (St. Louis), 77, 686-705.

—-, Klass, D. W., and Bickford, R. G. (1967). Cortical audiometry: an objective method of evaluating auditory acuity in awake and sleeping man. Trans. Amer. Acad., Ophthal. Otolaryng., 71, 81-91.

Coles, R. R. A. (1971). Proc. roy. Soc. Med. In press. and Knight, J. J. (1965). The problem of noise in the Royal Navy and Royal Marines. J. Laryng., 79, 131-147.

Fowler, E. P. (1936). A method for the early detection of otosclerosis; a study of sounds well above threshold. Arch. Otolaryng., 24, 731-741.

Fox, M. S. (1960). Industrial hearing conservation programs. Critique of present medical efforts and accomplishments. Eye, Ear, Nose, Throat, Monthly, 39, 47-51.

Glorig, A. (1958). Noise and Your Ear. Grune and Stratton, New York.

and House, H. P. (1958). New, practical concept of hearing testing for use of the general physician. J. Amer. med. Ass., 166, 1719-1721.

Hattler, K. W., and Schuchman, G. I. (1970). Clinical efficiency of the LOT-Békésy test. Arch. Otolaryng., 92, 348-352.

Hayes, D. L. (1958). New York State loss of hearing legislation. Amer. industr. Hyg. Ass. J., 19, 389-392.

Hinchcliffe, R. (1959). Self-testing automatic-recording audiometry: an appraisal. J. Laryng., 73, 795-812.
Hood, J. D. (1962). Bone conduction: a review of the present position with especial reference to the contributions of Dr. Georg von Békésy. J. acoust. Soc. Amer., 34, 13251332.

- and Poole, J. P. (1966). Tolerable limit of loudness: its clinical and physiological significance. J. acoust. Soc. Amer., 40, 47-53.

Jerger, J. (1960). Békésy audiometry in analysis of auditory disorders. J. Speech Hearing Res., 3, 275-287.

- (1970). Clinical experience with impedance audiometry. Arch. Otolaryng., 92, 311-324.

Kerr, J. R. (1967). Noise problems connected with the manufacture of nylon and terylene yarn. Proc. roy. Soc. Med., 60, 1121-1124.

Lidén, G. (1969). The scope and application of current audiometric tests. J. Laryng., 83, 507-520.

Naunton, R. F. (1963). The measurement of hearing by bone conduction. In Modern Development in Audiology, edited by J. Jerger, pp. 1-29. Academic Press, New York and London.

Noble, W. G. (1970). A new concept of damage risk criterion. Ann. occup. Hyg., 13, 69-75.

Schneider, E. J., Mutchler, J. E., Hoyle, H. R., Ode, E. H., and Holder, B. B. (1970). The progression of hearing loss from industrial noise exposures. Amer. industr. Hyg. Ass. J., 31, 368-376.

Stenger, H. H. (1956). Retinitis pigmentosa, symmetrische Innenohrschwerhörigkeit, typisch umgekehrtes vasculäres Fistelsymptom ohne Fistel und Erregbarkeitsstörung des Vestibularis. Arch. Ohr.-, Nas.-, u. Kehlk.-Heilk., 170, 187-198.

Symons, N. S. (1958). Workmen's compensation benefits for occupational hearing loss: an explanation of the law recently enacted in New York State. Noise Control, 4, no. 5 (Sept.), pp. 28-32.

Taylor, W., Pearson, J. C. G., Kell, R., and Mair, A. (1967). A pilot study of hearing loss and social handicap in female jute weavers. Proc. roy. Soc. Med., 60, 1117-1121.

Ward, W. D. (1963). Auditory fatigue and masking. In Modern Developments in Audiology, edited by J. Jerger, pp. 240-286. Academic Press, New York and London.

White Paper (1969). Industrial Noise and its Effect on Hearing. H.M.S.O., London.

Wilmot, T. J. (1969). Auditory analysis in some common hearing problems. J. Laryng., 83, 521-527.

Received for publication February 26, 1971. 